\title{
Review: Quantitative Methods and Legal Decisions
}

\author{
Lea Brilmayer $\dagger$ \\ Lewis Kornhauser ††
}

In the last century, legal scholars have expended considerable effort exploring the foundations of the law. Legal historians have exhaustively examined the sources of legal institutions and legal doctrines. ${ }^{1}$ Philosophers of law have inquired extensively into the nature of law and legal argument in attempts to explicate the basis of legal duties and their relationship to moral duties. ${ }^{2}$ In the course of these endeavors, however, relatively little attention has been paid to how and to what courts and legislatures know. ${ }^{3}$

Until recently these questions of knowledge have been answered only implicitly. The judicial process, for example, has followed a model of using common sense and community wisdom as the basis of how and what is known. Thus, the courts have assumed that the task of finding the facts to which the law must apply should be assigned to juries of twelve people, who are to draw upon their experience and knowledge. Similarly, when a judge must make broader findings of fact, he does so by taking judicial notice of facts that, because they are so commonly recognized, are beyond dispute. The model of legislative action ordinarily accepted is that the interplay of interest groups sifts the relevant facts and leads the legislators to the appropriate result. In those few embarrassing areas in which the need for technical knowledge has been overwhelming, decisions have been consigned to administrative agencies with appropriate technical staffs, and the results often ignored.

The interplay between knowing and judging and between knowing and legislative valuing can no longer be ignored by legal

$\dagger$ Assistant Professor of Law, University of Texas.

t† Assistant Professor of Law, New York University. The authors acknowledge the helpful comments of Glenn Shafer.

' See, e.g., L. Friedman, Contract law in America (1965); M. Horwitz, The Transformation of American Law, 1780-1860 (1977); 1 \& 2 F. Pollock \& F. Mattland, The History of ENGLish Law (2d ed. 1898).

2 See, e.g., R. Dworkin, Taking Rights Seriously (1977); H.L.A. Hart, The Concept of Law (1961); D. Richards, The Moral Criticism of Law (1977).

3 These inquiries have previously been the domain of the law of evidence. One aspect of the law of evidence bearing on these questions is the doctrine of judicial notice as it applies to "legislative facts." See, e.g., Turner v. United States, 396 U.S. 398, 405-19 (1970); Roberts, Preliminary Notes Toward a Study of Judicial Notice, 52 CoRnell L.Q. 210 (1967); Note, Social and Economic Facts-Appraisal of Suggested Techniques for Presenting Them to the Courts, 61 Harv. L. REv. 692 (1948). 
scholars, judges, or lawyers. Two factors have pressed this issue upon legal institutions. First, because of the increasing intrusion of the federal government into the economy and scientific research, courts and legislatures have confronted larger and larger numbers of technical disputes involving problems such as air and water quality, the safety and economics of nuclear generators, the deregulation of natural gas, and the presence of carcinogenic agents in the workplace and in the kitchen. ${ }^{4}$ In the midst of, and fundamental to, these questions lie difficult factual controversies that the law must, at least temporarily, resolve one way or the other. In many instances the particular resolutions of these controversies will determine the very content of the law or whether it should be imposed at all.

A second and perhaps related factor pressing this issue is that the manner in which our society understands itself has altered dramatically. Counting has invaded, indeed nearly conquered, the social sciences. We measure crime by incidence per hundred thousand and then compare the safety of neighborhoods and cities by these crime rates. Similarly, "health" means the incidence per hundred thousand of various diseases, and the diagnosis of economic ills relies on unemployment rates and various measures of industrial activity and consumer demand. Critics and proponents of our educational structure point to the changes in average reading levels and median mathematics scores. The fate of our cities is said to depend on migration patterns that are described and analyzed numerically.

As the number of numbers consulted has grown, the sophistication of the techniques used to anyalyze and interpret these numbers has also increased: instead of simple tabular presentations, courts and legislatures are apt to confront multiple regressions and the associated statistics-significance levels, correlation coefficients, and so forth. Thus, the language of factfinding together with the character of the disputes involved has thrust upon legal institutions a host of questions regarding the use of quantitative methods. To what purpose and in what circumstances should the law employ statistics and the methods of inference that accompany them? In what ways does it matter how thoroughly or by what means we know something when we announce a norm to guide action or when we invoke a norm to pass judgment? How much and what aspects of

1 Questions regarding the implementation of nuclear energy policy provide a prime example. See, e.g., Duke Power Co. v. Carolina Environmental Study Group, Inc., 98 S. Ct. 2620 (1978) (challenging statute limiting liability for nuclear accidents at federally licensed private nuclear power plants); Vermont Yankee Nuclear Power Corp. v. Natural Resources Defense Council, Inc., 435 U.S. 519 (1978) (challenging grant of license to nuclear power plant absent AEC rulemaking proceeding regarding safety of spent fuel disposal system). 
statistics need lawyers understand before they confront these pressing institutional questions?

Michael Finkelstein's new book, Quantitative Methods in $L a w,{ }^{5}$ barely raises the questions outlined above. ${ }^{6}$ Rather it collects a series of essays written and published individually over the past ten-to-twelve years, ${ }^{7}$ each dealing with some application of statistics or quantitative inference to a particular legal problem. ${ }^{8}$ As a rule, these essays have been widely noted and at times highly influential. The Supreme Court of the United States has discussed his models of jury discrimination and legislative redistricting, for example-endorsing the former, ${ }^{9}$ but refusing to adopt the latter. ${ }^{10}$ Other essays, particularly the essay on use of Bayesian inference in criminal trials, have been the subject of considerable academic discussion. ${ }^{11}$ Their collection in a single volume is likely to prompt new interest and controversy and thus raises anew the questions of the nature and vaildity of Finkelstein's project and its relationship to these larger theoretical issues.

In general, there are at least two potentially good reasons for collecting these articles into a book. First, if a common intellectual theory underlay all of these essays, drawing them together would cast light on the basic reasons why statistics or other quantitative methods might be useful in legal problem solving. Unfortunately, Finkelstein does not adequately outline the basic principles sup-

s M. Finkelstein, Quantitative Methods in Law: Studies in the Application of Mathematical Probability and Statistics to Legal Problems (1978) [hereinafter cited without cross-reference as FinKELSTEIN].

- What discussion there is is contained in his introductory chapter. FiNKELSTEIN ch. 1 ("Introduction to Quantitative Methods").

1 The only chapter that was not previously published is the introduction. Some of the other eight chapters have been updated or expanded since their initial law review publication. See FinKELSTEIN $\mathrm{x}$-xi.

3he applications vary from the derivation of statistical tests with which inference of jury discrimination may properly be made, Finkelstein ch. 2 ("Jury Discrimination"), to rules for the use of econometric models in administrative proceedings, FinkELSTEIN ch. 7 ("Regression Models in Administrative Proceedings"); from a proposal to instruct jurors on the principles of Bayesian inference, FinKELSTEIN ch. 3 ("Two Cases in Evidence"), to an analysis of guilty pleas in federal courts, Finkelstern ch. 9 ("Guilty Pleas").

- Castaneda v. Partida, 430 U.S. 482, 496 n.17 (1977).

10 Whitcomb v. Chavis, 403 U.S. 124, $146 \&$ n.23 (1970) (discussing a model suggested by Banzhaf, Weighted Voting Doesn't Work: A Mathematical Analysis, 19 RuTGers L. Rev. 317 (1965), and developed at greater length in chapter four of FinKELSTEIN). The unusual sense in which the model was "rejected" is discussed in the text at notes 37-50 supra. The Bayesian methods discussed in chapter three have also been rejected (at least in a rather simplified and distorted form) in People v. Collins, 68 Cal. 2d 319, 325-32, 438 P.2d 33, 36-42, 66 Cal. Rptr. 497, 500-06 (1968).

il Probably the best known critique is Tribe, Trial by Mathematics: Precision and Ritual in the Legal Process, 84 Harv. L. Rev. 1329 (1971). Finkelstein reprints a portion of his continuing debate with Professor Tribe in an appendix to the book. FinKelsTein 288-310. 
porting his quantitative inferences or probabilistic calculations. He scarcely provides enough explanatory material for a lawyer or other lay reader to follow the techniques actually employed, let alone develop a sense of the appropriateness of quantitative inference generally, or even an ability to adapt these techniques to closely analogous questions. Nor does Finkelstein offer theoretical arguments that would establish an intellectual relationship between the two disciplines and thus indicate that the essays are all instances of a single general intellectual perspective on the role of statistical inference in law. In fact, on closer examination, it does not seem that the essays do share common ground, unless it is mere reference to statistical techniques. ${ }^{12}$ Finkelstein himself admits that the selection is "persistently haphazard."13

A second possible justification for the book is as a survey of the different uses to which statistics has been put in law. A survey is not expected to provide a comprehensive intellectual framework, and Finkelstein's failure to attempt one suggests that his intended goal was to summarize and collect, and nothing more. Other existing collections of applications of statistics to legal or social policy questions aspire to fill this sort of need, ${ }^{14}$ and since they, in contrast, deal with policy formulation generally and not legal questions specifically, Finkelstein's book could fill a hitherto vacant spot in the literature. Yet as a survey, the book has serious defects, primarily because it is consistently argumentative rather than expositive..$^{15}$ Finkelstein's constant insistence that statistical methods be adopted for all manner of legal problems needs the support of an intellectual framework relating the two disciplines. Absent such an argument for preferring the values advanced by such use of statistical methods to all others-such as a desire for intelligent participation by lay juries, ${ }^{16}$ or even continuation of tradition-his discussion should be more objective and rigorously critical. The sorts of arguments Finkelstein offers on behalf of his methods would be sufficient for a legal brief, but not an intellectual inquiry.

12 In this respect the book compares unfavorably with Professor Posner's Economic Analysis of Law, R. POSNER, Economic ANALYsis of LAw (2d ed. 1977), which for all the criticism it has received presents a provocative and-more to the point-coherent intellectual argument about the common nature of legal and economic reasoning.

13 Finkelstern ix. At one point he does state that the "leitmotif" of the book is that "significant legal issues have been obscured by misconceptions of evidence or by ambiguities in the intuitive formulation of statistical ideas." Id. at 16.

"See, e.g., Statistics and Public Policy (W. Fairley \& F. Mosteller eds. 1977); Statistics: A GutDe to the UnkNown (J. Tanur ed. 1972).

is Some of Finkelstein's proposals have already been rejected, see note 10 supra; others may never be accepted.

16 This value is cited by Tribe, supra note 11, at 1391-93. 
Most importantly, Finkelstein's solutions are weak in one of the most crucial aspects of all quantitative inquiry: initial formulation of the abstract model. As Finkelstein realizes, ${ }^{17}$ perfect technical implementation of a model does not guarantee scientific accuracy, since the most difficult part of quantitative modelling is not carrying out the computations, but selecting which computations to do. Unfortunately, in most instances his awareness does not lead him to explain or justify his choice of models so that the reader will be able to appreciate or criticize the factors motivating the decision. Even when the assumptions underlying his chosen model are highly controversial, he does not give the reader a clue that certain reputable statisticians have dismissed them as fallacious. ${ }^{18}$

Despite these objections, the book has, for us, been curiously provocative. To some chapters, we would find ourselves nodding in agreement, acknowledging the validity of the statistical application. To others, we would react violently and struggle to articulate the nature of our often separate and irreconcilable objections. The book then serves as an elaborately worked out set of hypotheticals on which to test ideas about the distinctions that the law and lawyers ought to make in using statistics and statistical inference. To the discriminating reader, the book is a challenge to attempt to construct a coherent set of criteria for evaluating quantitative models in the legal context. In elaborating our criticisms of Finkelstein's models, we hope to make some initial observations about these criteria in anticipation of the increased role statistical models will undoubtedly play in the future of legal problem solving.

\section{The Modelling Process}

Construction of a model is, in essence, a process of abstraction and simplification. ${ }^{19}$ The scientist cannot include in his model all of the attributes of a real world phenomenon; an all-inclusive model, if it did not simply restate the phenomenon, would be too unwieldy. Instead, the scientist makes judgments about which of many possible details are most relevant and attempts to capture them through an appropriate formulation of premises and definitions. This process of selection suggests at least two preliminary considerations that must be kept in mind when evaluating the appropriateness of

"Finkelstein 11-14.

18 See note 91 infra.

" See generally M. Friedman, The Methodology of Positive Economics, in Essays IN Positive Economics 3 (1953); C. Hempel, Aspects of ScIentific Explanation and Other Essays in the Philosophy of Science (1965); K. Popper, The Logic of Scientific Discovery 27 (1968). 
a particular model: the precise purpose for which it is intended and the decisionmaker for whose use it was formulated.

\section{A. Purposes of Statistical Models in Law}

The suitability of a model necessarily varies with the purposes to which it is put. Consider the familiar, nonquantitative model of a "criminal profile" used in identifying airplane hijackers: ideally, the profile distills those characteristics of individuals that may make them suspect and suggest closer police attention. Such a profile may also be intended for use in determining whether an individual's behavior is so suspicious that it constitutes cause for a frisk or an arrest. The optimal profile for identifying "suspicious" behavior in the airline situation may not be optimal on the street. Moreover, that empirical data demonstrate the utility of a model in one situation does not conclusively justify its application to another. As Finkelstein seems to acknowledge, a sensitivity to context is an essential step in evaluating the appropriateness of any statistical model. ${ }^{20}$

Finkelstein's own models fall roughly into two groups. For some, the intended purpose is to provide a descriptive "summary statistic." For example, in his essay on economic concentration, Finkelstein proposes a new measure for the degree of concentration in a market. ${ }^{21}$ To the courts, the degree of concentration serves as a proxy for the degree of competition in that market, an important element of many antitrust cases and antitrust policy generally. Finkelstein defends his measure by saying that it more accurately reflects the true degree of concentration and competition than the measures currently in use. That is, he alleges that the proposed measure is a better, more accurate summary statistic of evidence on concentration than are the statistics currently employed. Another example of his use of summary statistics is his proposed analysis of voting power in his chapter on redistricting. ${ }^{22}$ Charging that the Supreme Court has attempted to equalize voting power of all citizens without a clear idea of what voting power is, he suggests using a probabilistic formula based on the likelihood that an individual will cast the tie-breaking vote in an election. ${ }^{23}$

A second group of Finkelstein's proposals entails the use of true statistical inference rather than statistical summarization of data. Regression analysis, for example, is generally used to determine

* See Finkelstein 13.

"Id. ch. 5 ("Economic Concentration").

2 Id. ch. 4 ("Voting").

Id. at 105-20. 
whether, how, and to what extent different variables are causally related. Thus, to take an example not addressed by Finkelstein, if wages are shown to be correlated with race or sex in a Title VII suit, "causal relationship" is tentatively assumed. ${ }^{24}$ Finkelstein describes several possible uses of regressions-for example, predicting the effects of increased rates-in the context of administrative agency decisionmaking. ${ }^{25} \mathrm{He}$ also proposes using Bayes's Theorem to analyze data about a suspected criminal as a basis for drawing inferences about whether he in fact committed the crime in question. ${ }^{26}$

The line between summary and inference may in some cases be blurred. For instance, use of statistics to analyze whether racial discrimination influenced the selection of grand or petit jurors can be viewed as either. ${ }^{27} \mathrm{~A}$ showing that a given pattern of selection would happen randomly only once in ten million trials could be used to support a strong inference of actual "historical" bias. The Supreme Court's continued attention to possible mechanisms by which discrimination might have been practiced apparently relies on such an approach. ${ }^{28}$ Alternatively, the "one-in-ten million" figure

${ }^{24}$ The emphasis must be on the word "tentatively." Because of the ever present danger of spurious relations between groups of data, such a showing constitutes only a prima facie case, which may be rebutted by the defendant. See generally Note, Beyond the Prima Facie Case in Employment Discrimination Law: Statistical Proof and Rebuttal, 89 HaRv. L. REv. 387 (1975).

${ }^{25}$ Finkelstein ch. 7 ("Regression Models in Administrative Proceedings").

23 FinKelstein ch. 3 ("Two Cases in Evidence"). For a more extensive discussion of Bayes's Theorem and the uses to which Finkelstein attempts to put it, see Part II C infra.

${ }^{27}$ Compare also the different treatment of statistics in constitutional and Title VII discrimination cases. In Griggs v. Duke Power Co., 401 U.S. 424 (1971), the Court held that, for purposes of Title VII, a statistical showing that a facially neutral employment test has a disparate impact establishes a prima facie case of employment discrimination. Unless shown to be job-related, the test would be defective under the statute regardless of the good faith of the employer. In contrast, Washington v. Davis, 426 U.S. 229 (1976), held that in constitutional challenges to facially neutral employment tests, mere statistical disparity does not establish a prima facie case; some showing of invidious intent was also required. The Title VII test may therefore be considered a definitional "summary statistic"; the constitutional test seems to be a true statistical inference of actual historical intent.

${ }^{2 x}$ In the most recent case on this issue, Castaneda v. Partida, 430 U.S. 482 (1977), the Court viewed a jury selection process using a list showing the Spanish surnames of the plaintiff class as one possible discriminatory mechanism. It is not clear whether the Court viewed this fact as necessary to the holding, although it seems wrong to conclude as Finkelstein does, Finkelstein 55, that in Castaneda the Court took the long-awaited step to a definitional approach.

Finkelstein asserts that statistical disparity should be enough:

[T] he larger point is that bad faith should not be the test. The inquiry is the discriminatory system, and the issue presented by such a system is the extent to which officials must take affirmative steps to produce nondiscriminatory results. Regardless of intent, if the officials administer a system which has the effect of excluding. disproportionate numbers of blacks or other groups from jury service, they should be chargeable if that result could have been avoided by means that lie within their legal duty. 
can be cast as a descriptive statistic used to define one of the constituent elements of "discrimination." In other words, such a pattern, even if unintended, can be viewed as inherently discriminatory, thus warranting remedial action. A definitional or "summary statistic" approach may be justified-and indeed preferable to one based on historical inference-when direct information about whether "actual" discrimination occurred is likely to be unavailable.

Despite this area of ambiguity and overlap, the distinction between a summary statistic and statistical inference is an important one. For example, the process of validating a summary statistic differs significantly from the process of validating a method of inference. A summary statistic directly links a theoretical concept with some measurable characteristic of the world. We evaluate the statistic by considering how well it captures the concept and how closely it conforms to the data presented by the event. For instance, economists and antitrust lawyers use a variety of methods to measure competition in an industry, such as the four-firm concentration ratio, the eight-firm concentration ratio, and the Herfindahl index. ${ }^{29}$ In each case, the economist or lawyer seeks to connect the concept of price interdependence and the size and number of firms in an industry with some statistics of industry composition. The four-firm concentration ratio does not completely meet the requirements of a useful summary statistic since we can observe industries with identical four-firm concentration ratios but different distributions otherwise, and for which we would expect different types of behavior. ${ }^{30}$ Thus, whether a summary statistic is "good" or "useful" is determined not only by studying a body of data, but also by considering the policies and theories that dictate such a study.

Unlike a summary statistic, a rule of statistical inference is not designed to connect a theoretical concept and the world the theory

Id. at 57-58. Either Finkelstein is unaware of Washington v. Davis, 426 U.S. 229 (1976) (holding that proof of discriminatory intent is required in constitutional cases), see note 27 supra, or he means, without mentioning the case, to suggest that it should be overruled. Nowhere in his book does he cite the decision. While Washington involved employment tests, the reasoning in the case was broad enough to cover jury discrimination as well; in fact, the analysis started with a discussion of Strauder v. West Virginia, 100 U.S. 303 (1880), a jury case. The Court discussed the jury discrimination cases in a paragraph of deliberate dicta, which extended the Washington test to that context. Castaneda, which Finkelstein does discuss, does not purport to overrule, limit, or distinguish Washington, but cites it approvingly for the proposition that "an unofficial act is not unconstitutional solely because it has a racially disproportionate impact." 430 U.S. at 493.

2 See generally Posner, Oligopoly and the Antitrust Laws, 21 STAN. L. REv. 1562 (1969).

* Finkelstein points out some of the difficulties with traditional measures at the outset of his chapter on economic concentration. FinKEISTEIN 133-34. 
seeks to explicate. Rather, a rule of inference indicates which set of factual conclusions may be drawn from a set of premises or facts. To follow a rule of statistical inference is to make a "valid argument." To determine which rules of statistical inference are valid or which statistical arguments are convincing requires consideration of epistemological and logical questions: How do we know? How do we justify our beliefs? What is a legitimate inference from a "true" fact? Consider the example of the criminal profile. If we could know by independent means which people are in fact criminals or are contemplating a crime, we could choose one profile (one inferential technique) over another by comparison of their respective success rates and the types of failures each made. While in some situations we may lack an independent, certain source of knowledge against which to test our particular inferential strategy, ideally an inferential model should aspire to meet this test of empirical validity. ${ }^{31}$

Finkelstein appears oblivious to such subtleties, since he offers the same sorts of justifications for all of his models, namely vague arguments that seem to address the model's innate aesthetic appeal rather than either its usefulness in making a theory operational or its validity as a rule of inference. His "entropy measure" of economic concentration is a prime example. ${ }^{32}$ What proposal cries more loudly for economic analysis than one for measuring concentration in markets? Finkelstein is so intent on the mathematical properties of his model and so superficial in his treatment of economic sources, however, that one might suspect him of being totally unaware of prior economic analyses. Similarly, when he deals with inference, such as his Bayesian model of "rational" jury deliberations, he offers no empirical arguments to support his assumption that his model leads to more accurate conclusions than do intuitive models. ${ }^{33}$ As with his economic model, Finkelstein relies instead on the internal appeal of his mathematics.

\section{B. Institutional Suitability}

The second preliminary consideration in evaluating a model is the person or institution for whose use the model is intended: we would formulate the criminal profile differently depending on whether it is intended for use by seasoned police officers, rookies in training, or lay persons. Similarly, statistical models may be more or less apt depending on whether they are directed towards legisla-

31 See authorities cited at note 19 supra.

3 FinKeistein 55-70.

2 See text and notes at notes 68-115 infra. 
tures, courts, or administrative agencies.

In suggesting the use of statistics and statistical techniques, Finkelstein does not discriminate among these three different institutional contexts. He does not ask in what ways it matters for whose use statistical techniques are specifically intended. Most fundamentally, courts, legislatures, and agencies perform different functions. In very crude terms, courts resolve disputes arising from past actions, legislatures announce rules to govern future actions, and agencies monitor ongoing, complex courses of behavior. ${ }^{34}$ The lawyer, usually attuned to the functions and requirements peculiar to each of these institutions, would naturally want to know how compatible or incompatible the use of statistics is with each institution individually, and thus which specific information or procedure is appropriate in each context. Considerations of structure and competence frequently underlie legal argument; they should apply as well with respect to the proposed introduction of quantitative techniques and statistical data into the legal arena. Indeed, one of the best chapters in Finkelstein's book sets out a specific protocul for using regression analysis in one institutional context, namely that of administrative hearings. ${ }^{35}$

Finkelstein fails, however, to give due consideration to the peculiar problems of applying statistics to judicial decisionmaking. Although it has been commonplace to note that courts do "make law," it is equally clear that they do so in a manner significantly different from legislatures or administrative agencies. First, the factfinding body in the court generally concerns itself with what happened in a particular dispute. Especially in a criminal adjudication, we do not conceive of the jury's factfinding as an investigation into the social facts necessary to determine the optimal rule for influencing future conduct of potential criminals. Indeed, most criminal prosecutions do not require the development or presentation of social facts-information about how people in general behave-at all. In the legislative context, on the other hand, predictions about the impact of a proposed rule on large communities of individuals may greatly influence evaluation of the rule. Thus the use of summary statistics, especially adoption of summary characterizations of data, naturally appears more appropriate in the legislative setting than in the courtroom: Legislators cannot avoid confronting facts about the frequency of events or about the distribution of various characteristics in a population, since in announcing

3 This distinction is sometimes expressed by saying that courts are "backward looking" or retrospective while legislatures are "forward looking" or prospective. See, for example, Justice Holmes's opinion in Prentis v. Atlantic Coast Lines, 211 U.S. 210, 226-27 (1908).

33 FrnkelsteIN ch. 7 ("Regression Models in Administrative Proceedings"). 
rules to govern future conduct the legislature must speak in general terms.

Second, problems arise even when the judicial use of statistics might be appropriate. Unlike agencies or even legislatures, courts do not provide a congenial forum for the development of social and statistical facts. In an adversary proceeding, the parties seldom develop positions adverse to their own. At the same time, the most compelling interpretation of statistical data or tests might run counter to the interests of all parties before the court, and a judge who is untrained in and unfamiliar with statistical techniques cannot be expected to realize the inadequacy of the adversarial positions. As Finkelstein points out, even administrative agencies with technically competent staffs tend to resolve disputes over econometric models, for example, in an inappropriate manner. ${ }^{36}$

Third, most court decisions are extraordinary, final events. In many administrative law situations, on the other hand, the person whose interest is primarily affected by the adjudication has a longterm regulatory relationship with the agency. In rate-making proceedings, for example, the utility will have an opportunity, as quantitative methods and understandings alter, to relitigate a particular issue and introduce new facts or new interpretations of facts. The same potential for learning and reconsideration is simply not present in the courtroom. This difference suggests that courts should be more hesitant than other legal institutions to adopt controversial techniques.

One might think that proposed judicial use of statistics would be least open to institutional criticisms in the field of constitutional interpretation, since in that area the judge's "legislative" function is more pronounced. Yet Finkelstein's models of constitutional interpretation are even more troublesome than his proposed statutory revisions. One example is the measure of voting power he suggests for use in analyzing redistricting cases. Finkelstein relies on a model first suggested by Max Banzhaf, ${ }^{37}$ which argues that the proper measure of a citizen's voting power is the likelihood that his vote will determine the outcome of an election. Basically, a citizen's voting power is defined as the fraction of elections that would be tied if he did not vote. Under this definitional approach to voting power, it is mistaken to attempt to compensate for different sizes of electoral districts by a proportionate distribution of legislative power.

36 Chapter 7 ("Regression Models in Administrative Proceedings") details the ways in which he thinks their procedures erroneous.

${ }^{7}$ Finkeistein 114-21. See Banzhaf, Multimember Electoral Districts-Do They Violate the "One Man, One Vote" Principle? 75 YALE L.J. 1309 (1966); Banzhaf, supra note 10. 
Thus if one district is twice the size of another, an assignment of two representatives to the larger (or of two votes to a single representative of the larger) may overcompensate for the population difference. Under Finkelstein's and Banzhaf's formula, the voting power of an individual does not vary according to population, but rather with the square root of population. The resulting computations are quite complicated, especially when adjusted to take into account the different probabilities of different pluralities in an election. Still, according to Finkelstein, the results reached under this model are preferable to the ones reached by the Supreme Court in Fortson v. Dorsey ${ }^{38}$ and Kilgarlin v. Hill, ${ }^{39}$ cases that have looked to sheer population size of the districts and have required direct proportionality of electoral size and number of legislators.

A fatal weakness in Finkelstein's approach is its misunderstanding of the federal court's institutional constraints in reapportionment cases. In the reapportionment decisions that he cites; the Court has been in a posture of passing on plans formulated by state legislatures or lower courts, a variety of which plans have been found constitutionally acceptable. Nothing the Court has said indicates that the Banzhaf plan would not also be permissible. In fact, in Whitcomb $v$. Chavis, which Finkelstein misleadingly characterizes as "rejecting" the Banzhaf plan, ${ }^{40}$ the Court merely concluded that a legislative scheme was not unconstitutional per se for failure to conform to Banzhaf's formula. ${ }^{41}$ In case after case, the Court has emphasized that a state has a wide range of options with respect to legislative districting and that "mathematical exactness is not required in state apportionment plans." 42 Conformity with Banzhaf's formula, then, which embodies a single idea of optimal assignment

38379 U.S. 433 (1965).

386 U.S. 120 (1967).

4 Finkelstein 116.

"Whitcomb v. Chavis, 403 U.S. 124, 144-47 (1971). Finkelstein's interpretation of Kilgarlin v. Hill, 386 U.S. 120 (1967), is similarly misleading. He argues that when the Supreme Court noted that the addition of several legislators would eliminate certain existing discrepancies, it was imposing proportional-weighted voting. Finkerstern 106. This is not so. The Court was merely concerned with rebutting the state's assertion that it would be impossible to remedy flagrant disparities without disrupting political subdivision lines. "[W]e are not convinced that the announced policy of the State of Texas necessitated the range of deviations between legislative districts which is evident here." Kilgarlin v. Hill, 386 U.S. at 123. Of course, to prove that a nondisruptive remedy was possible, the Court did not need to canvass all the permissible options. It did not in this opinion comment on the permissibility of the Banzhaf plan.

12 Chapman v. Meier, 420 U.S. 1, 22 (1975) (dictum) (mathematical exactness not required); White v. Regester, 412 U.S. 755, 764 (1973); Kirkpatrick v. Preisler, 394 U.S. 526, 530-32 (1969); Swann v. Adams, 385 U.S. 440, 444 (1967) (dictum); Reynolds v. Sims, 377 U.S. 533, 569 (1964) (dictum) (mathematical nicety not a constitutional requisite). 
of votes, should not be conclusive in determining whether a particular legislative plan is within the permissible range. As the Court explained in Gaffney $v$. Cummings: ${ }^{43}$

We doubt that the Fourteenth Amendment requires repeated displacement of otherwise appropriate state decisionmaking in the name of essentially minor deviations from perfect censuspopulation equality that no one, with confidence, can say will deprive any person of fair and effective representation in his state legislature.

In effect, Finkelstein's approach is institutionally inappropriate as a standard of review because traditionally courts will defer to reasonable legislative solutions. Perhaps Finkelstein has mistakenly equated the standards for determining whether a violation exists with the standards for judicial formulation of a remedy once a violation is found, for the latter standards do specify a single "constitutional solution." As the Supreme Court stated in Chapman v. Meier, "4 "a court ordered plan . . . must be held to higher standards than a State's own plan." Yet Banzhaf's formula cannot even be used in judicially formulated reapportionment orders. The Supreme Court has frequently and consistently held that absent unusual circumstances, court-ordered plans should utilize single-member districts ${ }^{45}$ because of the various difficulties that result from multimember districts, difficulties that Banzhaf's formula does nothing to cure. ${ }^{48}$ Again, monolithic analysis of "voting power," no matter how ingenious, appears insensitive to institutional realities.

Furthermore, in the reapportionment cases, the Supreme Court has, on a number of occasions, refused to take a numerical approach

is 412 U.S. 735, 749 (1973). The deviation that has preoccupied Finkelstein and Banzhaf is particularly unimportant given that inequalities at the voter and legislature levels tend to cancel each other out. If one district is twice the size of a second, then a voter in the first district has a smaller chance to break a tie. If the legislator from the larger district gets two votes, however, the utility to the voter from the first district of breaking a tie is greater. Thus, while the legislator is overcompensated by weighted voting, this balances against the citizen's relative inability to affect his choice of representatives.

4420 U.S. 1, 26 (1975).

is Wise v. Lipscomb, 98 S.Ct. 2493 (1978) (citing cases); East Carroll Parish School Bd. v. Marshall, 424 U.S. 636, 639-40 (1976); Connor v. Williams, 404 U.S. 549 (1972); Connor v. Johnson, 402 U.S. 690, 692 (1971). Banzhaf's formula tells us how "best" to adjust voting weights when setting up multimember districts; when districts of equal size are used, it is irrelevant.

"Chapman v. Meier, 420 U.S. 1, 15-16, 20 (1975) (outlining reasons for preferring singlemember districts, none of which relate to Banzhaf's objections). See also Wise v. Lipscomb, 98 S.Ct. 2493, 2498 n.5 (1978); Whitcomb v. Chavis, 403 U.S. 124, 134 n.11 (1971) (demonstrating winner-take-all effect of multimember districts). 
to set constitutional limits on what a legislature may validly do, thereby casting doubt generally on the application of quantitative models to adjudication in this field. ${ }^{47}$ There are at least two institutional reasons why courts might hesitate to become involved in formulating or adopting numerical standards for constitutional interpretation, even if the subject matter is properly theirs. One is that numerical formulas may be perceived as illegitimate because they are implausible derivations from the constitutional text. Although fidelity to the framer's intent is not the only consideration in constitutional interpretation, historical continuity is still a valuable source of legitimacy for judicially formulated standards. As demonstrated by the controversy over the adoption of numerical standards for how long into pregnancy abortion remains a constitutional right, ${ }^{48}$ precise quantitative formulas are difficult to defend against charges of arbitrariness. Setting limits on legislative variation from ideal districting presents the same problem, since the text does not speak in quantitative terms. In the Supreme Court's words: "Neither courts nor legislatures are furnished any specialized calipers that enable them to extract from the general language of the Equal Protection Clause of the Fourteenth Amendment the mathematical formula that establishes what range of percentage deviations is permissible, and what is not." 49 An opaque technical standard such as the Banzhaf formula is even more open to serious objections of implausibility than such limits on percentage deviation among districts.

A second reason to hesitate is that mathematical formulas, being models, are simplifications. As such they do not attempt to incorporate all potentially relevant features of the phenomena they purport to describe. This feature of quantitative models poses special problems in those areas, such as constitutional interpretation, in which a flexible, case-by-case approach may be most desirable. If the formula is adopted as only one factor out of many, the benefits of predictability and precision do not accrue. Yet to adopt the formula as determinative in and of itself is even less desirable since its simplifications will preclude sensitive consideration of the factual variations present in cases arising later. Redistricting formulas are

17 Roman v. Sincock, 377 U.S. 695, 710 (1964). See also Kirkpatrick v. Preisler, 394 U.S. 526,530 (1969) ("The whole thrust of the 'as nearly as practicable' approach is inconsistent with adoption of fixed numerical standards which excuse population variances without regard to the circumstances of each particular case.").

4 See Roe v. Wade, 410 U.S. 113, 163-65 (1973).

- Mahan v. Howell, 410 U.S. 315, 329 (1973). Cf. Fnnkelstein $51-52$ (regarding technical formulas). 
no exception; indeed, consideration of the complexities Banzhaf's model fails to take into account suggests that the factors it actually quantifies may be the least important ones. To avoid this dilemma, the Court has opted instead for a flexible, case-by-case approach that will allow it to deal with unanticipated and unquantifiable factual variations:

What is marginally permissible in one state may be unsatisfactory in another, depending on the particular circumstances of the case. Developing a body of doctrine on a case-by-case basis appears to us to provide the most satisfactory means of arriving at detailed constitutional requirements in the area of state legislative apportionment. ${ }^{50}$

This case-by-case treatment, the traditional judicial approach to complex problems, seems more appropriate than the use of mathematical formulas that are both implausible and rigid. Finkelstein's models are all the more inappropriate because they are not attuned to the needs of the institutions he purports to consider.

A particular statistical model may be unsuitable even when these preliminary considerations are satisfied, that is, even when deliberately designed with sensitivity to the institutional setting and purpose for which the model is intended. We will consider below two reasons why a statistical model may be unacceptable: first, it may fail to capture accurately the important features of the phenomenon it purports to describe; second, it may be ethically unsuitable.

\section{Descriptive Accuracy of Statistical Models in Legal SETTINGS}

Because a model is necessarily an abstraction and a simplification, the decision regarding what features are essential and must be retained will in most instances not be a scientific or statistical one. Thus, the model is judged not by its internal mathematical consistency, but rather by its fidelity to the external phenomenon under consideration..$^{51}$ When a model purports to describe a legal phenomenon, its relevance must be judged by legal criteria; when it purports to describe rational thought processes, it must conform to our concepts of rationality. Many of Finkelstein's models are weak because he treats carelessly the phenomena he wishes to describe. We will demonstrate this carelessness by reference to two of his legal

st Reynolds v. Sims, 377 U.S. 533, 578 (1964).

st See authorities cited in note 19 supra. 
models, those of guilty pleas and voting power, and one model of a nonlegal phenomenon, that of rational jury deliberation.

\section{A. Guilty Pleas}

In his chapter on the constitutionality of guilty pleas, Finkelstein advances clever statistical arguments to the effect that not all persons who plead guilty would in fact be convicted should they choose to stand trial. "On the basis of the analysis that follows," he writes, "I conclude that the pressure on defendants to plead guilty in the federal courts ... [has] induced a high rate of conviction by 'consent' in cases in which no conviction would have been obtained if there had been a contest." 52 The point of his analysis is to dispute the Supreme Court decisions upholding plea bargaining as constitutional, for the arguments in those cases "manifest an assumption that those who are induced to plead guilty would, in any event, be convicted." 53

Whether or not one agrees with the results upholding negotiated pleas, Finkelstein's characterization of the Supreme Court's reasoning in Brady $v$. United States ${ }^{54}$ is unfair. The Court did not mean to imply that all persons who plead guilty would be convicted; for instance, at one point the majority opinion in Brady, from which Finkelstein quotes, explicitly refers to the advantages to the prosecutor of obtaining a plea in cases in which "there is substantial doubt that the State can sustain its burden of proof." 55 The language Finkelstein seizes upon to buttress his interpretation of the Court's reasoning is the Court's observation that "for a defendant who sees slight possibility of acquittal, the advantages of pleading guilty and limiting the probable penalty are obvious."'5s Arriving at this conclusion is not, of course, the same as saying that the defendant would be convicted if he chose to go to trial; rather, the Court was suggesting that, because of his estimate of the likelihood of conviction, the defendant thinks a plea is a better deal. One can even cast the Court's conclusion in probabilistic terms if one wishes: the defendant weighs his estimate of the likelihood of various outcomes at trial and the desirability of those outcomes against the desirability of the negotiated plea. In effect, all the Court was sug-

32 FINKELSTEIN 265.

33 Id. at 264 . He repeats this misinterpretation of what the Court assumed. Id. at 9 \& 22.

st 397 U.S. 742 (1970).

ss Id. at 752. It is unclear why Finkelstein interprets the Court's opinion as he does, since this quotation from Brady is reprinted in his text. FinkelsTzin 264.

ss 397 U.S. at 752, quoted in FINKRLSTEIN 264. 
gesting was that, from his pretrial point of view, the defendant thinks that pleading guilty is to his benefit. This conclusion is certainly plausible. If the defendant knows he is guilty, or even if he believes he is innocent, he may estimate the likelihood of conviction to be high, and he will compare that likelihood to the proportionate reduction in sentence the prosecutor offers..$^{57}$

One can, of course, still attack the Court's reasoning on many grounds. ${ }^{58}$ Is the plea really fair given that the defendant may be in a poorer position than the prosecution to evaluate the probability of conviction? Are not many defendants pressured into accepting pleas they do not really estimate to be to their advantage? Is there not something fundamentally wrong with a criminal justice system that operates by negotiation? Should we ever allow incarceration of even a guilty defendant if there would not be sufficient evidence to prove guilt beyond a reasonable doubt? The Supreme Court could no doubt be accused of giving these issues insufficient consideration.

Alternatively, one could defend the Court's reasoning. For example, one might argue that the primary purpose of the "reasonable doubt" standard is to protect innocent persons from conviction, with an unfortunate cost being that many guilty persons go free. Thus it could be said that if the defendant admits guilt, it is no objection that there is insufficient other evidence to prove the case beyond a reasonable doubt. The point is that arguments such as these are where the real dispute lies. Few persons would defend plea bargains on the simplistic and implausible argument Finkelstein imputes to the Supreme Court-namely that persons who "cop a plea" would be convicted at trial anyway. Finkelstein's model addresses itself to an interesting but, for the Court's purposes, almost irrelevant question; the real issues, such as those mentioned above, are tossed off as a sidelight to the mathematics. ${ }^{59}$ Ironically, he states in another portion of the book, that "mathematical analysis of evidence changes impressions of the underlying factual context, and by that process suggests that the issues for legal judgment are rather different from those seemingly presented when the decisionmaker accepted the horizons of his intuitive view." $60 \mathrm{He}$ apparently views such a development as beneficial. We believe, however, that legal thought should not be diverted to the wrong questons merely

\footnotetext{
${ }^{57}$ We do not mean to suggest that anything is to be gained by a probabilistic phrasing.

ss See Langbein, Torture and Plea Bargaining, 46 U. CHr. L. REv. 3 (1978).

39 These are mentioned in FINKELSTEIN 280-81.

"Id. at 16.
} 
because they are more susceptible to quantitative analysis than are the right questions. ${ }^{61}$

\section{B. Voting Power}

A second legal phenomenon to which Finkelstein applies quantitative models has already been alluded to: measurement of voting power. As argued above, institutional considerations make Finkelstein's and Banzhaf's model an inappropriate one for courts that must decide reapportionment cases. In addition, an analysis of voting power based upon the probability that an individual's vote will break an otherwise tied election is too simplistic and implausible to be of much use even by institutions other than courts.

Many complex factors have motivated the reapportionment decisions. One theme that has figured in many of these decisions is the unfairness of retaining apportionment schemes that have become outmoded because of shifting population patterns. In particular, the imbalance of urban-versus-rural power (and later, urbanversus-suburban power) resulting from shifting concentrations of population has made reapportionment necessary. ${ }^{62}$ Legislatures have failed to reapportion their seats for the obvious reason that individual legislators have a vested interest in the status quo. Variations on this theme in other cases have included deliberate gerrymandering of districts and dilution of the political voice of racial minorities. ${ }^{63}$

Quantitative analysis, specifically the adoption of a single mathematical formula, has proved to be an inadequate mechanism to detect and remedy the broad spectrum of abuses of the electoral system. First, the suggested formula is not indicative of or responsive to the motivations of legislators; it measures neither good faith nor discriminatory intent. If a legislature has invidious intentions of gerrymandering or preserving unfair political advantage, a precise statement of how far they may go will only facilitate discrimination. If, on the other hand, a legislature has demonstrated good

" Cf. id. at 11 ("[T]here is a tendency, which must be scrutinized in each case, to sweep away complexity to permit mathematical accessibility. This drive for quantification sometimes tempts the mathematician to ignore or reject complicating factors that are nonetheless essential to the legal picture.").

22 See, e.g., Reynolds v. Sims, 377 U.S. 533, 567 n.43 (1964) ("Although legislative apportionment controversies are generally viewed as involving urban-rural conflicts, much evidence indicates that presently it is the fast-growing suburban areas which are probably the most seriously underrepresented").

w White v. Regester, 412 U.S. 755 (1973); Whitcomb v. Chavis, 403 U.S. 124 (1971); Burns v. Richardson, 384 U.S. 73 (1966); Fortson v. Dorsey, 379 U.S. 433 (1965); Gomillion v. Lightfoot, 364 U.S. 339 (1960). 
faith, and the main sources of population disparities or dilution of voting power are legitimate considerations such as a desire to preserve traditional political or community boundaries, an evaluative model should allow greater latitude. As the Court has noted, however, "[a]n unrealistic overemphasis on raw population figures, a mere nose count in the districts, may submerge these other considerations and itself furnish a ready tool for ignoring factors that in day-to-day operation are important to an acceptable representation and apportionment arrangement." 64 Moreover, a single mathematical model is too simplistic a device to take into account the greater flexibility permissible in legislative, as opposed to court-ordered, and in state legislative, as opposed to congressional, districting plans. ${ }^{65}$ Banzhaf's formula, which focuses on a voter's ability to break a tie election, ${ }^{86}$ is no exception; it makes no allowance for any of these variables. ${ }^{67}$ In light of these considerations, the Court's relative inattention to precise mathematical measurement of disparities in district size and voting power is sensible. As with guilty pleas, choice of variables in Finkelstein's model seems based more upon their susceptibility to quantification than their importance in the legal context.

" Gaffney v. Cummings, 412 U.S. 735, 749 (1973); cf. Fortson v. Dorsey, 379 U.S. 433, 440 (1965)(denouncing judging reapportionment cases "in terms of simple arithmetic" as a "sterile approach").

ws Chapman v. Meier, 420 U.S. 1, 27 n.19 (1975); Connor v. Williams, 404 U.S. 549, 550 (1972); Reynolds v. Sims, 377 U.S. 533, 578 (1964).

a This analysis is particularly problematic in that it suggests inquiry into factors the courts have considered irrelevant, such as party alignment. For example, this model suggests that a Republican in a "safe" Democratic district would have no voting power. Finkelstein attempts to reconcile the Court's unconcern with this "deprivation" of voting power by erroneously assuming that the Court desires to establish "some model of the electoral process in which the only variable is the number of votes." FinKELSTEIN 107. As the cited case material indicates, the Court has consistently downplayed the importance of numbers. See text at note 37 supra.

"See, for example, Judge Breitel's dissent in Ianucci v. Board of Supervisors, 20 N.Y.2d 244, 229 N.E.2d 195, 282 N.Y.S.2d 502 (1967):

As for Mr. Banzhaf's helpful analysis, he modestly limits its value to the mathematical consequences and mathematical evaluations of weighted voting systems. He says, in his amicus brief, quite candidly, that his mathematical models do not purport to present a realistic picture of the actual operation of such systems "which of course would involve factors such as party politics and urban-rural interests which are not considered by these simple models." And that is what cases of this kind are about.

Id. at 258,229 N.E.2d at 202,282 N.Y.S.2d at 513 . Institutionally state courts are in a better position to impose a mathematical formula than federal courts, which should approve a wide range of permissible options. See text and notes at notes 40-43 supra. Because of the qualification mentioned in note 43 supra, Finkelstein disapproves of the result in Ianucci. FINKELSTEIN 112. 


\section{Bayesian Inference in the Trial Process}

Comparable modelling difficulties beset a third quantitative model proposed by Finkelstein: his advanced introduction of Bayes's Theorem ${ }^{88}$ into civil and criminal trials. ${ }^{89}$ Although the intended use is a legal one, the proposal is a specific instance of a general theory purporting to inform all "rational" processes of inference. The validity of this model will be considered in depth; the difficulties concern whether the axioms underlying Bayesian statistics really capture intuitive conceptions of rationality. We will argue not only that there is considerable doubt whether the axioms are valid generally, but also that they are particularly doubtful with regard to legal reasoning.

1. Testing for Validity. As a preliminary matter, we might ask why it is necessary to test the validity of the axioms of Bayesian statistics against intuitive notions. Normally, scientific theories are validated not by introspective analysis of whether the premises are intuitively satisfying, but by empirical testing of the theory's predictions. ${ }^{7}$ Indeed, this method of validation is uniformly considered the hallmark of the scientific method: theories are confirmed or discarded according to whether their inferences are borne out in practice. Theories about what constitutes a rational approach to problem solving need not be any different. Consider, for instance, recent developments in computerized poker playing. ${ }^{71}$ Computer programmers, working with experienced poker players, sought to

4 Argument over the validity of Bayesian theory-the idea that beginning with a belief based on a given body of evidence, one can calculate the probabilistic impact of additional bits of information-is a central theme in the statistical literature. For the Bayesian viewpoint, see B. de Finetti, Probability, Induction and Statistics (1972); D. Lindley, Bayesian Statistics: A Review (1971); D. Lindley, InTroduction to Probabitity ANd Statistics (1965); L. Savage, Foundations or Statistics (1950). For a more critical appraisal of Bayesian theory, see generally E. NAgel, Principles of THE Theory of Probability (1939); G. Shafer, A MathEMATICAL THEORY of EvidENCE (1976). Bayesians acknowledge themselves to be in the minority. See, e.g., D. Lindley, Introduction to ProbabiutTy AND Statistics 38 (1965) ("[W]e are pursuing an unorthodox approach. Most statisticians adopt a different attitude in which only frequency probabilities are admitted."). Because the Bayesian interpretation of statistics is controversial, many introductory texts give only minor attention to Bayesian methods. See, e.g., P. Bickad \& K. Doksum, Mathematical Statistics: Basic Ideas and Selected Topics (1977) (chapter 10 includes Bayesian decision rules without necessarily accepting Bayesian interpretation); P. Hoel, INTRoduction To Mathematical Statistics 372 (4th ed. 1971) ("although the Bayes approach may yield considerably better results in the sense of mean risk, the results may not be trustworthy"); R. Hogg \& A. Craig, Introduction to Mathematical Statistics (3d ed. 1970) (10 out of 400 pages are devoted to Bayesian methods). See also note 115 infra.

"Finkelstein ch. 3 ("Two Cases in Evidence").

1 M. FrIEDMan, supra note 19. See also authorities cited in note 19 supra.

"Findler, Computer Poker, Scientific AM., July 1978, at 144. 
model an optimal poker strategy by analyzing the elements of the most successful human approaches and combining them into a comprehensive program. The initial modelling attempts were too simplistic, so that reasonably skillful humans could trounce the machine. These first models were thus "disconfirmed" by empirical tests, necessitating sophisticated alterations and eventually resulting in more successful programs. Clues about how to alter the original program were supplied by human understanding about where and how it went wrong.

An important difficulty with using statistical inference about actual past historical occurrences, particularly in the judicial setting, is that the inference is not subject to the same sort of empirical verification. Introduction of Bayes's Theorem into criminal or civil trials is then curiously unscientific $\mathrm{c}^{72}$ because the conclusions of Bayesian inference in trials are in principle untestable. We would like to know, for instance, whether the probability figures resulting from its application are indeed more "accurate" than those intuitive assessments would provide. But it appears impossible to collect meaningful data about the respective accuracy of intuitive versus Bayesian methods-as we could in the poker program context by pitting the program against a skilled human player.$^{73}$ Absent the usual methods of assessing the success of this model of the "rational" approach to problem solving, the sole criterion for evaluating the model is whether the premises are intuitively satisfying. As we shall show below, there has been considerable debate about whether they are, and the proponents of Bayesian inference are probably in the minority.

2. Bayes's Theorem in Operation. Bayesian, or "subjective," statistics along with several other schools of statistics adopts as its premises what are known as "Kolmogorov's axioms" for probabil-

72 One author concludes that " $a$ conception of probability according to which we cannot in principle control by experiment and observation the probability statements we make (i.e., a nonfrequency one) is not a conception which recommends itself as germane to scientific inquiry." E. NAGEL, supra note 68 , at 50 .

The non-Bayesian inference used in discrimination cases is relatively immune to this objection. Even if the historical inference of discrimination is false, the statistical tests are still useful as an attempt to define discrimination. See notes 27-28 supra.

73 While we could devise experiments to compare results, see text at note 122 infra, we would not know which method was more accurate unless we could decide who was "really" guilty. One possibility would be to examine cases where evidence probative of guilt had been excluded as the fruit of an illegal search. This sort of comparison would not, however, uncover evidence of which method erroneously convicted more innocent defendants, only evidence of which erroneously acquitted more guilty defendants. Conceivably, a method could be devised to compare the increase in convictions when adopting Bayesian methods to the known percent of guilty persons acquitted. 
ity. ${ }^{74}$ For our discussion here, we list three of these axioms in a somewhat simplified form:

(1) $P(A)=0$ where $A$ is impossible

(2) $P(A)=1$ if $A$ is certain

(3) $P(A$ or $B)=P(A)+P(B)$ where $A$ and $B$ are mutually inconsistent.

A number of results follow from these axioms. First:

$$
P(A)+P(\text { not }-A)=1
$$

or, the probability of a proposition plus the probability of its opposite must add to one. This follows from axioms (2) and (3) since it is certain that either $A$ or not- $A$ is true, and in addition we know that $A$ and not- $A$ are mutually exclusive. A further result, Bayes's Theorem, ${ }^{75}$ follows once the idea of "conditioning" is introduced. If we define $P(A / B)$ as the probability that $A$ is true given that we already know that $B$ is true, then

$$
P(A / B)=\frac{P(A) P(B / A)}{P(A) P(B / A)+P(\text { not }-A) P(B / \text { not }-A) .}
$$

These axioms, and the theorems derived from them, of themselves supply only a mathematical structure for a theory. They are neither true nor false, ${ }^{76}$ and Bayesian statistics cannot be faulted scientifically until its significance for the real world is known. In order to supply a model for some real-world phenomenon, the axioms must be "interpreted"; that is, we must specify more clearly what we mean by terms such as $P(A) .{ }^{77}$ Various schools have offered competing interpretations for the probability axioms cited, two of which interpretations are relevant here. ${ }^{78}$ One, the "frequency" in-

"The discussion of these axioms contained in the text is unfortunately but necessarily quite simplified. One excellent, although technical, exposition of different axiom schema and their interpretations is T. FINE, TheorIEs of ProbabiLITY (1973). In the final analysis, Fine prefers the Bayesian formulation despite the difficulties he outlines. Id. at 240.

${ }^{75}$ The theorem is named after Thomas Bayes, an 18th century English clergyman. Historical accounts of probability theory can be found in I. Hacking, THe EMERGence op Probability 73-110 (1977), and I. Todhunter, A History of the Mathematical Theory of Probabilty from the Time of Pascal to That of Laplace 294-300 (1865).

7 E. NAGEL, supra note 68 , at $27,39$.

77 For instance, calculus and differential geometry can be "interpreted" through the laws of Newtonian mechanics to give us a theory about balls rolling down inclined planes and planets revolving around stars. We can then test the interpreted theory for empirical validity. It is entirely possible to have two contradictory axiom systems such as Euclidean and non-Euclidean geometry and find that each is "true" when it is confined to its appropriate sphere.

"A third theory is the "logical" school. It assumes that probability is "an objective logical relation between propositions analogous to the relation of deducibility or entailment." 
terpretation, corresponds to the lay conception of probability. We may think of some repeatable activity such as flipping a coin, throwing a pair of dice, or dealing a deck of cards, and we associate the probability of a given outcome with the frequency of its occurrence in repeated trials of the experiment. Under this interpretation, the values for $P(A), P(B)$, and so forth are obtained by counting up what percentage of times the outcome in question occurs. Although this theory proves to be problematic when it is impossible to count outcomes in this way, it has nevertheless been thought useful to apply to repeatable random events for which we can estimate probabilities by sampling. Unfortunately, it is of no help for studying nonrepeatable occurrences such as trials and crimes, since we are supposed to determine $P(A)$ by direct observation of how many times the outcome $A$ occurs. ${ }^{79}$

Another approach, generally associated with the names of de Finetti and Savage, is the subjective or personalist school, ${ }^{80}$ which applies the interpretive scheme generally referred to as "Bayesian." Here the probability is regarded as revealing something about the person observing the world rather than the structure of the world itself. In the process of making decisions, an individual must estimate the likelihood of events. $P(A)$ is thus interpreted to mean the "degree of belief" the individual has in propostion $A$. This school of probability argues that the decisionmaker's beliefs about the likelihood of events conform to certain rationality requirements embodied in the axioms quoted above; it then uses a mechanism, Bayes's Theorem, for adjusting prior beliefs on the basis of new evidence. The event need not be repeatable, and the initial probability is obtained by introspection, not counting or logical deduction.

E. NAGEL, supra note 68, at 48; see note 68 supra. This interpretation is potentially applicable to the trial situation. Although it is not equivalent to the "subjective" school, since probabilities are not degrees of confidence but objective statements about logical statements, some of the objections we state apply to this school also. Other arguments can be advanced against the logicists that cannot be made against the Bayesians. Since these arguments are both more technical and wedded to the philosophical context from which they arise, we have chosen not to discuss them. The logical position is as much a minority one as the personalist one discussed in the text, and the thrust of our argument is not to settle on the proper approach but rather to demonstrate that Finkelstein has not sufficiently acknowledged that a controversy exists.

7 E. NAGEL, supra note 68 , at 23 ("Every probability statement of the form thus far considered is a factual statement, into whose determination empirical investigations of some sort must always enter. Probability statements are on a par with statements which specify the density of a substance; they are not formulations of the degree of our ignorance or uncertainty. . . . Since the explicit definition of probability statements is in terms of relative frequencies, the direct evidence for them is of a statistical nature.").

so E. NAGEL, supra note 68, at 44. See generally T. Fine, supra note 74; G. SHArER, supra note 68. 
Finkelstein applies Bayes's Theorem in the following way. Suppose, he says, a woman's body is found in a ditch. Furthermore,

[t]here is evidence that the deceased had a violent quarrel with her boyfriend the night before. He is known to have struck her on other occasions. Investigators find the murder weapon, a knife whose handle bears a latent palm print similar to the defendant's. The information on the print is limited so that an expert can say only that such prints appear in no more than one case in a thousand. ${ }^{81}$

The total probative value of the evidence is to be assessed in the following way. First, the jury evaluates $P(G)$, a prior probability of guilt based on the unquantifiable data: the violent argument, the defendant's murderous propensities, and so forth. The quantifiable evidence about the palm print is then combined with the prior probability to reach a posterior probability, using Bayes's formula

$$
P(G / H)=\frac{P(G) P(H / G)}{P(G) P(H / G)+P(\text { not }-G) P(H / \text { not }-G)}
$$

where $P(G / H)$ is the posterior probability we seek (guilt "given" the hand print), and $P(H / G)$ is the probability that a hand print was found, given that he is guilty. $P($ not-G) is the probability of "not guilty" on the original evidence, and similarly $P(H / n o t-G)$ is the probability that his print matches if he is not guilty. ${ }^{82}$

Finkelstein asserts that $P(H / G)$ will be one, since $P(H / G)$ is the probability that the hand prints match (the "new" evidence) given that the suspect is guilty, and the prints will certainly match if he is the real murderer. Finkelstein then sets $P(H / n o t-G)$ equal to .001 , for $P(H / n o t-G)$ is the probability that his hand print would match given that he is not guilty, and that is the same as the probability of a match between the murderer and a random member of the population. The juror's initial estimate of guilt, $P(G)$, then, need not be terribly high to damn the defendant. If the prior $P(G)$ equals $.1,^{83}$ for example, the posterior $P(G / H)$ will equal .991 .

What does this .991 mean? Finkelstein is not very clear on this point, although he does understand such figures to be applicable to differing degrees of belief, ${ }^{84}$ thus parting company with the frequentists who assert that this application is not meaningful. The prepon-

\footnotetext{
8t FinKeLSTEIN 85.

22 Id. at $87-90$.

s $P($ not-G) will equal .9 , since $P(G)+P($ not $-G)=1$.

a Finkelstein 63-65.
} 
derance of the evidence standard, for instance, would probably be satisfied by a degree of belief of .5 or greater.$^{85}$ But Finkelstein at times also gives his results a frequency interpretation in order to make them more acceptable to the lay reader. Thus, he asserts that if we group together a large number of cases with probability of .51 for the plaintiff, a verdict allowing recovery would be right 51 percent of the time.$^{88} \mathrm{He}$ justifies this interpretation on the ground that "[t]here is in fact no significant difference between the subjective definition of probability applied to unique events and the classical definition based on relative frequency." ${ }^{97}$ Only unfamiliarity with, or disregard of, an enormous body of literature on the subject-including that of Bayesian statistics-could lead him to say this. The Bayesians are as emphatic as anyone else that subjective probabilities cannot be given a standard frequency interpretation..$^{88}$

Furthermore, it is wrong to say that if we affirm a proposition in which we have a degree of belief of more than one-half "we would be right more than half the time." 89 We have not the slightest assurance that any of the evidence on which we base our judgment is correct-how then can we know what percentage of times it is true? A more accurate statement of the Bayesian view is that if we have

ss Id. at 66-67. Essentially the same point of view has been presented by other authors. See, e.g., Ball, The Moment of Truth: Probability Theory and Statements of Proof, 14 Vand. L. Rev. 807, 822-30 (1961); McBaine, Burden of Proof: Degrees of Belief, 32 CaLIF. L. Rev. 242, 260-62 (1944). Cf. MCCormick's HandBooK of THE LAw of Evidence 794 (2d ed. E. Cleary gen. ed. 1972) (proof by a preponderance is "proof which leads the jury to find that the existence of a contested fact is more probable than its nonexistence."). See also R. EGGLeston, Evidence, Proof, and Probability ch. 9 (1978) ("Standards of Proof").

Finkelstein also suggests situations in which other civil standards apply, such as when the goal is to distribute error evenly between defendants and plaintiffs rather than to minimize error. FinKELSTEIN 67.

st See FinKELSTEIn 64.

87 Id.

s See, e.g., D. Lindley, Introduction to Probability and Statistics 32 (1965).

Professor Nagel-not himself a Bayesian-argues forcefully that the two interpretations are not compatible.

Now it has often been assumed that, if we possess no information to the contrary, these antecedent probabilities are equal to one another. This assumption has been supported by what is known as the Principle of Indifference. With the help of this principle it has been supposed that probabilities could be determined a priori-that is, without recourse to empirical, and more particularly to statistical, investigations. . . . [F]or a relative frequency conception of probability the equating of probabilities to one another simply because we know no reason why they should be unequal is a major error.

E. NAGEL, supra note 68 , at 30-31.

We have been unable to locate a scholarly statistical source that asserts that the two interpretations are interchangeable.

so FINKELSTEIN 64. He makes an identical error when he states that "[s]eemingly unique events may be grouped together with respect to the degree of belief they inspire, and the probability of the uncertain event in each case expressed as the relative frequency of such events over all cases in the class." Id. See note 72 supra. 
a degree of belief of .51 , this figure is the equivalent of saying that we think that out of one hundred cases we would be right fifty-one times, not that we would be correct fifty-one times. Put a different way, two jurors in a criminal trial might both vote to convict, but one may have a .995 certainty and the other a .999 certainty. We cannot say for sure how many errors each will make after one thousand convictions, only how many each would expect. This corrected interpretation reconciles the book's analysis with the Bayesian school, although it is doubtful whether all "subjectivists" would be completely comfortable even with this reformulation..$^{90}$

3. Bayesian Statistics and the Principle of Additivity. Whether or not Finkelstein's analysis can be made compatible with Bayesian methods, Bayesian statistics themselves remain open to serious objections. Enormous controversy surrounds the foundations of statistics, and in particular the Bayesian claim that their model adequately represents degrees of rational belief and the processes of rational inference. The weakest point in the Bayesian interpretation of the underlying axioms concerns the axiom of additivity, which states that $P(A)$ plus $P($ not $-A)$ must equal one. ${ }^{91}$ Such an assumption is natural for the "frequency" interpretation of Kolmogorov's axioms mentioned above; ${ }^{22}$ the number of occurrences and nonoccurrences of any repeatable event must total to the complete number of trials. Under a Bayesian interpretation, however, this axiom means something different: when an individual adds his degree of belief in proposition $A$ to his degree of belief that $A$ is false, the total is one. This assumption makes considerable sense if one conceives

- De Finetti apparently had such an interpretation in mind. B. DE FINETT, supra note $68, \S 9.6$, at 209-28.

"Finkelstein does not acknowledge that a large group of well-known statisticians, including Jacob Bernoulli, refused to accept the additivity principle as applied to degrees of belief; the controversy that rages today goes back even to the founders of the discipline.

In 1921 Keynes wrote that "[m]any candid persons, when confronted with the results of probability, feel a strong sense of the uncertainty of the logical basis upon which it seems to rest. It is difficult to find an intelligible account of the meaning of 'probability' or of how we are ever to determine the probability of any particular proposition; and yet treatises on the subject profess to arrive at complicated results of the greatest precision and the most profound practical importance." J. KEYNES, A TrEatise on ProBaBILITY 51 (1921). In a similar vein, Ernest Nagel, an eminent methodologist and logician, opened a book on the foundations of probability by stating that "an analysis of what is meant by 'probable' which would meet the unanimous approval of competent students of the subject cannot be given at the present state of research." E. NAGEL, supra note 68 , at 4.

The controversy is so great that one author commenting on the foundations of statistics concedes, "[i]t is not without reason that the professional philosopher and the plain man can now make common cause in a suspicious attitude towards statistics." Hogben, The Contemporary Crisis or the Uncertainties of Uncertain Inference, in The SIGNIFICANCE TesT Controversy at 8 (D. Morrison \& R. Henkel eds. 1970).

${ }^{22}$ See text at notes 78-79 supra. 
of the decisionmaking process as a gamble. The assumption simply forestalls someone from making book against the decisionmaker: the assumption ensures that an artful gambler could not take advantage of the decisionmaker by betting for and against a certain outcome, thereby guaranteeing that the gambler will always come out ahead.93

Although one might simply respond to Finkelstein's use of additivity in criminal cases by noting that no bookmaker confronts the judge or jury in such situations, a more compelling objection is that additivity is not always a necessary condition of rational decisionmaking. Indeed, a decisionmaker need only be aware of the potential trap of being induced into two inconsistent bets to avoid the loss. He may then decide to introspect more carefully, consider gathering more information about the likelihood of $A$ and not- $A$, or make a decision based on some criterion distinct from maximizing expected value. Each of these three tactics may present complex, unsolved intellectual problems for the decisionmaker, but it is not obvious why, in adopting one of them, he would be acting irrationally. One rational strategy that does not fit the Bayesian model is a court's finding of "insufficient evidence," that is, that a party simply has not adduced sufficient evidence to warrant disturbing the status quo. ${ }^{94}$ That the Bayesian system does not adequately account for a conception such as "sufficient evidence" becomes clear upon examining the premise of additivity at greater length.

Thoughtful statisticians have been bothered by the assumption of additivity because it means that our confidence in either $A$ or not$A$ must be greater than or equal to one-half. If both were less than one-half, they could, of course, not total to one. It seems implausible to assume, however, that when we have little or no evidence about the truth or falsity of a statement we must be more than half sure that it is true, or else more than half sure that it is false. ${ }^{95}$ Bayesians

3 An artful gambler could take advantage of a person who fails to follow the additivity principle by offering two lotteries. In one, the person pays the gambler $\$ 4$ if event $A$ occurs and receives $\$ 6$ if event $A$ does not occur. In the second he pays $\$ 7$ if $A$ does not occur and receives $\$ 3$ if $A$ does occur. If the person views the probability that $A$ will occur as .6 and that $A$ will not occur as .3, he will think both lotteries "fair" and be willing to bet. But if he takes both bets together, he is certain to lose one dollar.

At least one scholar dismisses this interpretation as "based on a dubious psychological theory." E. NAGEL, supra note 68 , at 46 . At a minimum, it does not adequately account for the possibility that the decisionmaker might choose not to play when he had too little information to estimate the probabilities accurately.

"In a civil case such a finding means that the plaintiff has not satisfied his burden of proof; in a criminal case it means that the state has failed to establish guilt beyond a reasonable doubt.

is This is a standard criticism of Bayesian belief schemes. See,. e.g., G. SHaFER, supra note 68 , at 23 (1976); authorities cited in note 68 supra. 
deny that it is possible to know absolutely nothing about a given proposition;:88 a prior belief in the truth of a proposition is necessary in order that, once new evidence is uncovered, we can calculate the posterior probability from it by application of Bayes's Theorem. To calculate prior degrees of belief when information about a proposition is wholly lacking, Bayesians ordinarily apply what is known as the principle of indifference: if we have no reason for preferring one proposition to another, then we assume their probabilities are equal. ${ }^{.7}$ Thus-to use the example of one critic of the Bayesian approach-if we have no evidence whatsoever about whether there are living beings in orbit around the star Sirius, then, according to the Bayesians, the probability that there is life is equal to the probability that there is not. ${ }^{98}$ Both probabilities equal one half.

But what if we had framed the question in terms of three alternatives that exhaust all the possibilities? For example, if we were also to wonder whether there are planets in orbit around the star, our alternatives are first, that there are no planets, second, that there are planets, but no life on any of them, and third, that there are planets that happen to have life. If we had initially considered the question in this light-with no evidence bearing on the issue-then we would, under the principle of indifference, have assigned each alternative a probability of one third. But the proposition that there is no life in orbit around Sirius now has a different probability assignment from the one it had when only two alternatives were considered. The problem is that there is no generally accepted a priori method of determining the number of alternatives to which equal probabilities will be assigned. ${ }^{99}$ Only after empirical

" De Finetti, a Bayesian, writes: "According to the subjective view, no problem can be correctly stated in statistics without an evaluation of the initial probabilities." B. DE FINETT, supra note 68 , at 143 . It seems more plausible that there are some questions for which we have no empirical data. Unless the subjectivists would argue that we are born with information bearing on every question that can be phrased in the English language, there must be a point at which we received our first piece of information about any given proposition. Before that point we had none.

"J. KeYNES, supra note 91, at 41. This principle is also known as "the principle of insufficient reason." Some Bayesians would say that we always have some information about every question. See G. SHAFER, supra note 68 , at 23-24.

is The example is borrowed from G. SHAFER, supra note 68, at 23-24. See also E. NAGEL, supra note 68 , at 47 . Keynes argues that it is no answer to try to count the number of contrary possibilities since there are always an infinite number: "not $A$, and $B$ " is a contrary to $A$ for all values of $B$. J. KEYNES, supra note 91 , at 43 . He also gives the following example. If we have no data about the population of France or Great Britain, we would say that it is as likely that a man is a citizen of one as of another. Likewise with France and Ireland. "And on the same principle he is as likely to be an inhabitant of the British Isles as of France. And yet these conclusions are plainly inconsistent." Id.

"At first glance it seems that we might be able to salvage the probabilities in the first 
evidence is received does it become possible to state that some alternatives are more or less likely than or exactly as likely as others. This puzzle has confounded many probabilists; in fact Keynes, whom Finkelstein cites in another context, ${ }^{100}$ concluded that this problem was sufficient to make the Bayesian belief scheme unworkable. At the very least, Bayesian schemes become highly problematic when a decisionmaker has little evidence on which to base a decision.

Contrary to what one might assume, the probability statement itself does not reflect the adequacy or inadequacy of the evidence. ${ }^{101}$ A juror's calculation of the probability of guilt does not necessarily measure the amount of evidence supporting the inference of guilt; it only indicates how strongly the available evidence suggests that the defendant is guilty. To see why this probability calculation does not measure the weight of the evidence, though, compare it to an assertion that I am fifty percent confident that when you draw a ball from an urn with one thousand balls it will be black. This statement might suggest that I myself filled the urn with five hundred black balls and five hundred white balls, and mixed them thoroughly. Or it might suggest that I did not observe the urn being filled, but drew and then replaced a sample of ten balls, and half were black and half white. I might not even have any assurance that there were no other colors represented in the urn. Or it might suggest that I have no information at all, but am assuming that black and white are equally possible alternatives. To handle these difficulties, other schools of statistical inference customarily supplement probability

Sirius hypothetical by splitting the likelihood of there being planets into cases in which there are inhabited ones, and cases in which there are not. The extreme and probably fatal difficulties with such an approach are discussed in the authorities cited in note 98 supra. How could one rationally assign belief in this way when it is clear, as Nagel points out, that "there is no logical relation between the number of alternative ways in which a coin can fall and the frequency with which these alternatives in fact occur?" E. NAGEL, supra note 68, at 47.

100 Finkelstein misleadingly cites Keynes, FinkELSTEIN 2-3, suggesting that Keynes would approve the sorts of methods Finkelstein espouses. Keynes discussed and rejected the Bayesian approach. J. KEYNES, supra note 91 , at 42.

iof One author who overall prefers the Bayesian approach as least incoherent warns:

Bayesian statistics can provide a false sense of security. It is neither rational nor wise to force what few crumbs of information we may possess about a parameter into the misleadingly detailed form of a distribution. It is a seeming defect of most of the current theories of subjective probability that they do not distinguish between those prior distributions arrived at after much experience and those based on only the vaguest forms of uninformed introspection.

T. Fine, supra note 74, at 231. Cf. E. NAGEL, supra note 68, at 11 (observing that some have a tendency to overrate the value of statistical techniques "on the assumption . . . that valuable results can be obtained from unreliable and insufficiently analyzed data by employing a sufficient number of signs of integration"). 
statements with higher-order probability statements or nonquantifiable qualifications-statements about the size of the sample, for instance-that bear on the weight of the evidence.

To return finally to the insufficient evidence question, it is clear that "weight of the evidence," an important concept in law, serves some functions distinct from that of allowing a comparison of the defendant's and plaintiff's probabilities relative to a given body of evidence. The legal system appears to contain separate requirements that some certain amount of specific evidence be adduced before a prima facie case is established. ${ }^{102}$ If the plaintiff in a civil case produces a minimal amount of evidence, a motion for a directed verdict may be granted even if the defendant has as yet introduced no evidence at all. This procedure seems to indicate that the legal system has methods of measuring the total quantity of evidence quite separate from and in addition to its methods of comparing the relative weight of the evidence on either side. Therefore, a probability figure that reflects the extent to which a given body of evidence supports an inference, but not the sufficiency of the body of evidence itself, cannot adequately capture all of the elements of legal proof.

4. Additional Problems. A few more brief examples should demonstrate further why Bayesian assumptions are particularly dubious in a legal setting. One involves the way we combine different issues within the same case. Suppose, for instance, that a contracts case poses issues of whether a proper contract was formed and whether its terms were complied with. If the jury is just barely convinced that the contract was formed-say at the 60 percent level-and also is just barely convinced that the plaintiff complied with his contractual obligation-say at the 70 percent level-then although the law would allow him to recover, Bayesian principles suggest the combined probability on the issues is significantly less than one half. ${ }^{103}$ Since plaintiffs are not entitled to recover in more than about 42 percent of such cases, ${ }^{104}$ they should be denied recovery in any particular case because it is improbable that the plaintiff's cause in that one case is meritorious. This objection could be met by raising the proof requirements for each of the formation and

:12 Cf. McCormick's HANDBooK of THE LAw of EvidENCE, supra note 85, at 783 (distinguishing burden of proof from burden of producing evidence).

ins This example is taken from L. Cohen, The Probable and the Provable 58-59 (1977), an insightful and challenging account of the difficulties in Bayesian proof schemes which attempts a non-Bayesian reformulation.

in We adopt here, for purposes of argument, Finkelstein's assimilation of a subjective definition of probability to a definition of probability based on relative frequency. See text and notes at notes 85-88 supra. 
compliance issues to a higher level, raising the probability level to fifty percent. But then we would have a higher level of proof for the contract formation (or compliance) issue than is normally proper when formation (or compliance) is the only issue.

A second problem regards impeachment testimony, and is based upon an example given by Jacob Bernoulli. ${ }^{105}$ The Bayesian assumption that the probability of some hypothesis relative to a given body of evidence must equal one minus the probability of the opposite hypothesis relative to the same body of evidence does not hold, according to Bernoulli and some latter day critics, when the particular evidence in question merely undermines the probative value of the rest. Impeachment evidence is clearly of this sort. Consider a case that turns on whether an automobile driver ran a red light. The pedestrian who is suing him for negligence did not see whether the light had changed and must rely upon the testimony of a single witness who says that it was still red. Unfortunately, cross-examination shows that the witness is somewhat forgetful, so that the jury grants him a credibility of only one half. Assessing the probability of negligence based on the evidence just described proves to be rather troublesome.

One solution might be to say that based upon the witness's testimony the probability that the defendant ran a red light is one half, and the probability relative to that single piece of evidence that the light had turned green is also one half. The problem is that if the jury thinks that the witness is so forgetful that his testimony can be assumed accurate only one half of the time this belief does not mean that half the time the witness is wrong. It means that half the time his testimony is not informative. The impeachment of the witness does not tell us that what the witness is saying is false; it merely negates the inference that it is true. The jury would be quite rational in describing its attitudes after hearing this evidence by saying that it was half convinced that the light was red, but had heard no evidence whatsoever tending to show that the light was green. This description of the probative value of the evidence is quite in line with the law's attitude towards impeachment evidence; the evidence could not be offered directly to show that the light was green, since it does not tend to show that the light was green. There is a difference between refuting a proof that is given and proving that the opposite is true. ${ }^{106}$

105 Bernoulli's ideas are discussed in I. Hacking, supra note 75; Shafer, Non-Additive Probabilities in the Work of Bernoulli and Lambert 19 Archive FOR Hist. Exacr ScI. $30 \dot{9}$ (1978). The example is adapted from Shafer's discussion.

104 This difference is particularly pronounced in mathematics, to which a comparison 
Third, Finkelstein himself does not always adhere to Bayesian methods, at least as he interprets them for trial use. In his chapter on jury discrimination, which immediately precedes his chapter on Bayesian inference, he adopts standard statistical techniques that are based upon non-Bayesian assumptions. For instance, the usual practice in cases in which a plaintiff uses statistical evidence to show a pattern of race or sex discrimination is to use "confidence levels" of 95 percent. Of this practice Finkelstein approves. ${ }^{107}$ Yet the meaning of this figure is that in only one case out of twenty could the complained-of activity occur at random, that is, occur without discrimination. ${ }^{108}$ This practice is, however, inconsistent with a Bayesian approach to proof of such issues, for under Finkelstein's description of that approach a plaintiff would only have to show that it was more likely than not that the defendant's acts were discriminatory, or in other words that out of one hundred such situations, such a result would occur at random less than half the time. Indeed, statistical proof in civil cases at the 95 percent confidence level would closely approximate the Bayesian standard of proof beyond a reasonable doubt. Given this example, it may be reassuring that Finkelstein does not adhere dogmatically to the Bayesian viewpoint.

A final difficulty arises from those few times Finkelstein appears to be aware that Bayesian methods conflict with intuitive assessments of probabilities. ${ }^{109}$ When faced with such evidence, he arrogantly construes it as demonstrating the insufficiency of intuitive reasoning. ${ }^{110}$ Mathematical methods, he asserts, must be adopted if "true judgment" is to be exercised." For instance, he cites a study in which psychologists showed that subjects do not combine evidence as Bayes's Theorem would require. ${ }^{12}$ When given

may be made. There are certain famous results, such as Fermat's last theorem, for which no proof as yet exists. A counterexample to the theorem would show it to be false; a proof would show it to be true. But if I offer a proof that is later shown to be fallacious, the theorem is not thereby demonstrated to be false, even though the proof that it is true has been refuted. It is a famous result in mathematical logic that a statement may be true within a theory without being provable. The reader who is interested in this analogy is referred to chapter 3 in L. CoHEN, supra note 103 ("The Completeness Issue").

in FinkELstern 36.

100 Id. at 42 .

is Id. at $3,59,62,70,92$ n. 57 .

II" E.g., id. at 70 ("a common but logically incorrect idea").

III Id. at 103. Finkelstein's argument that intuitive assessments of relative frequency are often incorrect, id. at 4 , is not germane here. Since frequency statements have empirical content they can, in principle, be empirically tested; it is the controversial subjective "degree of belief" interpretation that cannot.

${ }^{112}$ Id. at 72. The study to which he refers is Tversky \& Kahneman, Decisions under Uncertainty: Heuristics and Biases, 185 Scr. 1124 (1974). 
"background" evidence about the frequency of an event to establish a prior probability, and then some "particular" evidence about whether the event occurred, the subjects perversely paid much greater attention to the particular evidence than Bayes's Theorem would warrant, and paid relatively little attention to the generalized background evidence. This study, he concludes, shows how greatly we would benefit from instruction in Bayesian techniques. ${ }^{113}$

Such an attitude turns scientific open-mindedness on its head. Axioms are not normative: it is they, and not the phenomena they purport to capture in a model, that must alter their content in case of conflict. If the Bayesian axioms are designed to reduce to a model not actual thought processes, but ideal thought processes, then it is incumbent upon proponents of these methods to show that their models are in fact more rational. The difficulty is precisely the one that opened our discussion of Bayesian techniques: no empirical test has yet been devised to compare unguided intuition regarding degrees of belief with inference according to the subjectivist schema, and thus to assess which is empirically superior. On the precise issue of combining particular and general evidence, some examples suggest that the intuitive methods may be preferable. ${ }^{14} \mathrm{~A}$ book purporting to introduce lawyers to statistical techniques-to "correct" methods of reasoning-cannot afford to be so unscientific. ${ }^{.15}$

i13 Finkelstein 92 n.57.

III One such example, provided by Todhunter, is nowhere mentioned by Finkelstein, although he cites in another context a source discussing it. Todhunter, drawing from Condorcet, gave the following example regarding the implausibility of Bayesian combination of background and particular evidence:

Suppose for example a trustworthy witness asserts that one ticket of a lottery of 10,000 tickets was drawn, and that the number of the ticket drawn was 297 . Here if we put $p$ $=1 / 10,000$ we obtain such a very small value of the truth of the witness's statement that we lose our confidence in the formula.

I. TodhunTER, supra note $\mathbf{7 5}$, at 400 . To Todhunter, it was quite reasonable that the prior probability estimate of picking ticket 297 should be of little importance in assessing the likelihood that the witness is telling the truth. But Bayesian statistics does not allow the particular evidence to supersede completely the background probability, with the result that the probability of the witness's veracity becomes exceedingly small as the number of tickets in the lottery is increased. When the initial estimate is based upon scanty evidence or none at all, it is not clear that it should be accorded serious weight once some particular evidence is available.

IIs It is mystifying how Finkelstein can offer such a controversial methodology without acknowledging its difficulties. The sole indication that he even recognizes that a controversy exists is the following footnote, reprinted in its entirety: "For over two centuries debate has swirled about the validity of Bayesian analysis in scientific pursuits and the prior probabilities with which it begins. The issues are discussed in Joint Statistics Seminar, The Foundation of Statistical Inference (Bernard and Cox eds. 1962)." Finkeistern 93 n.59. This meager footnote is all the more striking since Finkelstein quotes and should therefore be presumed to be familiar with the work of a number of authors who have not accepted the Bayesian assumptions. See authorities cited in note 91 supra. In addition, a number of prominent 


\section{Ethical Suitability}

A final problem proponents of quantitative models must confront is ethical suitability. The technically unimpeachable use of a statistic or statistical method in appropriate form may still be open to normative objections. Professor Tribe, for instance, has objected on ethical grounds to the use of Bayesian methods of inference in the trial process. ${ }^{116} \mathrm{He}$ has argued that, regardless of the rate of error, the mechanical process of Bayesian inference so profoundly alienates both jurors and defendants that it should not replace the current "ritual" of trial. Tribe's arguments may go too far, however, since they might eliminate the use of statistics in many areas-such as Title VII disparate-impact claims-in which statistics is commonly considered proper.

A different problem arising from the use of statistics concerns the question whether such use denies litigants their rights to be treated as individuals. For example, suppose reliable statistical data established a link between the presence of an extra $Y$ chromosome in an individual's genetic makeup and a propensity for crime. One might object to the use of this evidence by legislatures and courts because it penalizes an individual for his "status," a factor beyond his control. Finkelstein is sensitive to this potential injustice, and none of his models seems to fall prey to this objection. ${ }^{117}$ Yet it would be extremely valuable to know how he might justify this normative intuition in the face of an apparent conflict with the search for accuracy. ${ }^{118}$

statistics texts explicitly label the theory as controversial and relegate it to a single chapter or even a few pages. See note 68 supra.

Even the Bayesians recognize that theirs is a minority view. See note 68 supra. A large literature exists on the topic, to which the above cited footnote is Finkelstein's only reference. See, e.g., T. FINE, supra note 74; J. KEYNES, supra note 91; G. SHAFER, supra note 68 . In a frequently quoted book, Ernest Nagel argued that

[i]n most problems it is not practically or theoretically possible to assign values to the antecedent probabilities in Bayes Theorem which could have any empirical significance. For this reason Bayes Theorem has only a limited use, and few writers today take it seriously as a means for determining the probability of a given hypothesis on the basis of given evidence.

E. NAGEL, supra note 68 , at 31 (emphasis added).

III Tribe, supra note 11.

${ }^{117}$ FINKELSTEIN 8 . There is a possible problem with using prior subjective probabilities derived from the conduct of other persons as the basis for Bayesian inference at trial. For instance, Finkelstein describes a model, relying upon general data in prior paternity cases, for determining paternity in a present particular case. Id. at 73-78. A more serious problem with this model, which results in a high background probability of paternity, is that the data becomes out of date as soon as it becomes known that the model has been adopted: the favorable inference based on data from earlier cases encourages false suits.

is The problem appears to be similar to that Hume recognized as inherent in theories of scientific induction. One modern account of this problem can be found in B. Russell, On 
The objection that statistics appears to deny people treatment as individuals could possibly arise even when the characteristic in question is under the individual's control. One wonders whether some of the objections to use of Bayesian methods do not stem from the sense that the trier-of-fact should be concerned with accuracy in the particular case, and not with an overall greater record of accuracy. The objection to the use of statistics or statistical inference thus bears some resemblance to objections to utilitarian ethics. ${ }^{119}$

Although in some situations it may be true that grouping evidence together for statistical purposes fails to treat the individual case on its own merits, ${ }^{120}$ careful analysis reveals some conceptual difficulties in making an "individual treatment" objection to use of Bayes's Theorem at trial. In what sense has the defendant been prejudiced by a failure to treat his case on an "individual" basis? The following hypothetical may help demonstrate the problem. Assume that we hold all criminal trials in the traditional manner, and a jury reaches and enters a verdict without use of statistical techniques. Immediately after this verdict, we present the jury with an explanation of Bayesian methods and ask them, for experimental purposes only, to reconsider the case. After a long series of cases, we

Induction, reprinted in The Basic Writings of Bertrand Russell (1961). Inductive inference-the conclusion that since the sun has risen every morning thus far, it will rise tomorrow-rests upon an unprovable assumption about basic similarities and continuities (tomorrow will be like the other days) that are themselves inductive.

The statistical problem is similar because underlying statistical inference is the assumption that a given new case will conform to data already collected. While this assumption is a practical way to proceed in the face of uncertainty it seems counter to ethical assumptions that human beings should be treated as unique.

119 For one discussion of the problems with utilitarian ethics, see R. DworkIN, supra note 2, at 94-100, 232-38. These difficulties, where pertinent, are not confined to Bayesian approaches.

${ }^{120}$ Consider for instance two different theoretically possible uses of statistics in housing discrimination cases. If a plaintiff tries to prove discrimination in a property owner's refusal to rent him a house, he should not be allowed to introduce data from the market as a whole that shows discriminatory patterns in the neighborhood. Cf. Bogen \& Falcon, The Use of Racial Statistics in Fair Housing Cases, 34 MD. L. Rev. 59, 70-72 (1974) (suggesting such data useful to trigger Justice Department investigation). The individual owner simply cannot be held accountable for the activities of others, just as he should likewise be unable to refute through general market statistics a showing of discrimination. Even if a utilitarian overview of the situation shows that it would result in greater overall accuracy to grant the would-be tenant a remedy, we would consider the evidence irrelevant to the particular case. In contrast, someone denied an apartment should be able to rely upon statistical arguments concerning the history of that particular landlord. The landlord cannot respond that use of statistics violates his right to individual treatment, for the data all concern his own past conduct. It is possible, however, that even this familiar case, like the one involving an extra $Y$ chromosome, should also turn on whether the proffered evidence concerns events that were within the defendant's control. 
can compare the two sets of decisions. How are they likely to compare?

Both Finkelstein and his critics assume that the number of convictions would be higher under the statistical methods. ${ }^{121}$ In fact, both Finkelstein and his critics apparently believe that the statistical methods are, in some unspecified sense, more accurate. ${ }^{122}$ For present purposes, we will lay aside our doubts on this score and assume that this assumption is correct. Two types of mistakes are possible: an innocent person might be found guilty, or a guilty person innocent. The "individual treatment" objection seems to rest upon some notion that in the pursuit of greater overall accuracy a larger number of mistaken convictions will occur. If the Bayesian assumptions are in fact accurate, however, this notion is not true. Bayesian analysis allows us to vary the figure at which we set proof beyond a reasonable doubt, thus increasing our conviction that innocent persons will not be found guilty. Setting the level of proof at a probability of .991 means that we believe nine out of every thousand convicted defendants would be innocent. We could increase the standard to .995 and reduce the number of individuals we believe wrongly convicted to five. Since we can decide how many "mistakes" of this sort we are willing to tolerate, we can set the probability so that we believe the likelihood of an unjust conviction to be the same as we strive for under the intuitive methods. Thus, we would believe that we have the same number of erroneous convictions under both models; the higher conviction rate under the Bayesian method would presumably reflect the fact that fewer guilty people would go free. 123 The "individual treatment" objection is probably not, therefore, pertinent to the use of Bayes's theorem at trial. Yet this conclusion does not excuse Finkelstein's failure to acknowledge adequately normative objections of this sort. By failing

121 Finketstern 104. He concludes that this result is acceptable since the convictions are "warranted" by the evidence. Tribe seems also to assume so. See Tribe, supra note 11.

122 Tribe, at least, does not directly challenge the validity of Bayesian assumptions. The difficulty with testing the empirical accuracy of statistical methods generally, is discussed in K. POPPER, supra note 19, at 146-214.

12 One objectionable possibility would be that different people are convicted under the two methods. Although it seems unlikely, it could be true that some traditionally disadvantaged group would suffer a disproportionate number of the convictions under one scheme or the other. Possibly, the intuitive methods of inference serve to mask prejudice against racial minorities. FINKELSTEIN 104. In the alternative, as pointed out immediately below, adoption of scientific methods might handicap defendants lacking access to technical experts. Bayesian techniques seem designed to increase the number of convictions of people who are actually guilty, without jeopardizing the innocent. Seen in this light, they serve the same purpose as plea bargaining. Yet Finkelstein apparently objects to negotiated pleas on the ground that they may result in a conviction that could not be obtained after a judicial trial. See text and notes at notes 53-61 supra. Yet, this would be true also of Bayesian methods. 
to address such questions, Finkelstein can only have retarded the introduction of statistics into those areas in which it is most appropriate.

One additional normative objection to the adoption of both inference and summary statistics in trial proceedings is worth noting. The admission of technical evidence or the adoption of technological methods favors those with access to experts. In criminal proceedings this advantage tends to create a bias against criminal defendants, in civil proceedings against "small" plaintiffs and defendants. The bias is exacerbated when the technique or technical evidence is highly controversial and difficult to refute. Mistaken application of difficult techniques may go unnoticed because defendants cannot afford a statistician. Even impeccable technique imparts a bias of sorts, for if only the state has adequate access to experts, then errors of mistaken acquittal may be avoided while errors of mistaken conviction go unnoticed. Most importantly, one should not expect a criminal defendant to resolve or illuminate adequately controversial technical debates, such as whether to adopt Bayesian methodology in the first place. It is appropriate to ask, as Finkelstein does not, whether the disadvantage to the defendant offsets whatever benefits accrue from the introduction of statistical techniques in this area.

Finally, it is important to resist the notion suggested by this book that finding the appropriate statistical model is a straightforward, though somewhat technical, problem. ${ }^{124}$ Nothing could be further from the truth. In particular, where opportunities for objective verification are scarce, adoption of a methodology takes on the characteristics of a value choice. At this juncture, the normative objections that apply even assuming that statistics is the most accurate method of appraisal become especially important. Although we may be willing to make small sacrifices of normative values for accuracy, there seems to be little reason to sacrifice them when the statistical premises are implausible, and the conclusions untenable or untestable.

\section{Conclusion}

It is appropriate for courts to hesitate in adopting new scientific techniques. Scientists are free to entertain tentative hypothèses; ideally, free inquiry will guarantee that unfounded theories will not stand the test of time. Judicial decisions, in contrast, are final, at

124 Finkelstein's occasional reminders that mathematical techniques can be seductive, see FinKELSTEIN 11-12, are apparently inadequate with regard to his own modelling attempts. 
least with regard to the parties before the court. Furthermore, since legal problems are subtle and complex, the unquantifiable variables may well dwarf the quantifiable ones and make numerical modelling futile. It is therefore understandable that courts have been reluctant to enter into a quixotic chase after precision. Finkelstein does not argue convincingly against this reluctance: he fails to develop both the ethical and epistemological implications of his models. Finkelstein's book stands as a reminder that before we throw ourselves into a frenzy of measurement, we should stop to think about what and why we measure. Our results will be less "precise," but more faithful to the legal setting. 